\title{
The Effects of Edible Coatings on the Postharvest Quality of Citrus Fruits as Affected by Granulation
}

\author{
İbrahim Kahramanoğlu $\left(\mathbb{D},{ }^{1}\right.$ Chuying Chen $\left(\mathbb{D},{ }^{2}\right.$ Zengyu Gan $\left(\mathbb{D},{ }^{2}\right.$ Jinyin Chen $\left(\mathbb{D},,^{2,3}\right.$ \\ and Chunpeng Wan (D) ${ }^{2}$ \\ ${ }^{1}$ European University of Lefke, Gemikonagi, Northern Cyprus, Via Mersin 10, Turkey \\ ${ }^{2}$ Jiangxi Key Laboratory for Postharvest Technology and Nondestructive Testing of Fruits \& Vegetables, \\ Collaborative Innovation Center of Postharvest Key Technology and Quality Safety of Fruits \& Vegetables in Jiangxi Province, \\ College of Agronomy, Jiangxi Agricultural University, Nanchang 330045, China \\ ${ }^{3}$ College of Materials and Chemical Engineering, Pingxiang University, Pingxiang 337055, China
}

Correspondence should be addressed to Chunpeng Wan; chunpengwan@jxau.edu.cn

Received 22 May 2020; Revised 11 June 2020; Accepted 12 June 2020; Published 1 July 2020

Academic Editor: Hadi Hashemi Gahruie

Copyright ( 2020 İbrahim Kahramanoğlu et al. This is an open access article distributed under the Creative Commons Attribution License, which permits unrestricted use, distribution, and reproduction in any medium, provided the original work is properly cited.

\begin{abstract}
The world population is growing day-by-day, while the available natural resources for agricultural production, i.e., soil and water, are rapidly decreasing. Moreover, consumer preferences are highly affected by some quality characteristics of food products, which can be classified as external, internal, and hidden attributes. Among the internal quality attributes, granulation is a significant factor damaging the inner quality of citrus fruits and reducing the consumer attraction. The main symptoms of granulation (also known as section drying, crystallization, or scarification) in citrus are shrivelling in juice sacs due to gel formation, hardening, white colour, and low extractable juice content. A well-known result of the granulation is the reduction in soluble solid concentration (SSC), total sugar, and titratable acidity (TA). Granulation is known to affect the citrus fruit quality all over the world. Since citrus is one of the world's most popular fruit species, it is highly important to identify and manage this physiological problem to help sustainable production throughout the world. Consumer's preferences have also been moving towards the use of eco- and environmental-friendly alternative methods in postharvest fruit storage, including edible coatings. Edible coatings act as a barrier for the air and water transitions through the surface of fruits which results in retarding the deterioration of fruits, preventing and/or controlling the microbial decay, improving the fruit quality, and hence extending the storage duration. The mechanism of citrus fruit granulation is highly associated with the oxidative stress, and edible coatings have been reported to significantly reduce granulation and improve the quality of the fruits. In line with this information, this review article aimed to summarize the reasons, results, and managements of granulation of citrus fruits.
\end{abstract}

\section{Introduction}

Citrus is the leading fruit crop throughout the world and best suited to grow in Mediterranean countries, China, America, and Brazil. The total area devoted to citrus production is about 7.8 million hectare. The total production of oranges, mandarins, lemons, grapefruits, and others was about 73.3, $33.4,17.2,9.0$, and 13.5 million tons, respectively, in 2017 [1]. Citrus fruits are rich in nutrients, antioxidants activities, ascorbic acid, and phenolic and other bioactive compounds and are traditionally and scientifically known to be very beneficial for human health $[1,2]$. Citrus fruits are among the most important fruits in world trade (import/export), and the consumer's demand on the citrus fruits has been increasing throughout the world mainly because of the scientifically accepted health benefits and high antioxidant and high ascorbic acid contents. However, citrus fruits suffer from numerous production and postharvest problems, including pests, diseases, weeds, fruit cracking, yield problems, and postharvest quality loss. Granulation at the juice sac is 
one of the most important problems causing quality loss and reducing the consumer attraction [3].

The granulation (also known as section drying, crystallization, or scarification) in citrus fruits mostly appear when the fruits are kept on-tree after ripening with an extended harvesting period which significantly affects the individual juice vesicles within the segments, and the most important symptom is the solid and dry nature of the fruit segments. This can also happen in postharvest storage for almost all citrus species [4-6]. The juice sacs of affected fruits shrivel because of gel formation become hardened and granular with low extractable juice content and white colour [3, 7-11]. However, the granulation can also develop after harvest during storage and significantly affects the marketability of the citrus fruits. The granulated fruit vesicles become solid, enlarged, and discoloured. The granulation is generally associated with the fast growth of the large size fruits which is common in young trees $[4,12]$. The soluble solid concentration (SSC) and titratable acidity (TA) have also known to be reduced in the granulated fruit vesicles [4]. Further studies also showed that the granulation in citrus fruits causes secondary cell wall formation and thickening in the cell wall [13]. Previous studies have reported that the onand off-tree storage, fruit size, and juice vesicle position have a significant influence on the granulation of grapefruits (Citrus paradise Macf.). It was found that the granulation is higher in the stylar juice vesicles than in others. Studies have also shown that the larger fruits (about $600 \mathrm{~g}$ ) have higher granulation than smaller fruits. It was also noted that the ontree storage (late harvesting) significantly increases the granulation in grapefruits. On the other hand, early harvest and storage at high temperatures $\left(21^{\circ} \mathrm{C}\right)$ were found to increase the susceptibility of the fruits to granulation. Therefore, if the fruits are meant to be stored for later consumption, ontree storage is more effective to reduce granulation at the large size grapefruits [5]. However, previous studies have also showed that the granulation in the late-season fruits mostly appears in storage after harvest $[12,13]$.

Biological activities continue in the harvested fruits and vegetables, whereas the water and gaseous exchange with surrounding environment happens through transpiration and respiration. Thus, these phenomena result in the water and solute loss which significantly reduces the postharvest quality and storability of fresh products. There are several chemical and nonchemical methods used in postharvest handling practices. However, numerous studies reported significant hazards on human and environmental health caused by mis- or excessive-use of agrochemicals and the acceptability of agrochemicals by consumers have been decreasing. One of the successful methods used in postharvest handling practices to maintain postharvest fruit quality is the application of edible coatings alone or incorporated with plant extract, essential oils, and active metabolites $[14,15]$. Edible coatings act as a barrier for the movement of water and air on the fruits' surface which reduces the transpiration and respiration. This reduces water loss, delays fruit senescence, and increases antimicrobial properties of fruits $[16,17]$. The commercial use of waxes as edible coatings began around the 1920s; however, the use of edible coatings in postharvest handling of fruits and vegetables is an old technique dating back to the 12th century in China. Edible coatings are composed of food-grade materials, and in addition to retard fruit deterioration, coatings may cause several physicochemical changes which delays or prevents fruit granulation [17].

There is a gap in the published literature about the use of edible coatings in the management of citrus granulation. Therefore, this review aims to summarize the main causes and mechanisms of the granulation in citrus, its effects on the postharvest storage quality, and its management by edible coatings.

\section{Main Causes and Mechanism of Granulation}

As described above, granulation can be described as a preand postharvest problem which resulted in shrivelling of the juice sacs due to gel formation and solid, enlarged, and discoloured fruit vesicles (Figure 1). It is common for large size fruits and generally associated with the fast growth of the fruits $[4,12]$. The extractable juice content of the affected fruits decreases mainly because the moisture is binding to the cell walls or in gels [4]. These gels are the main causes of cell wall thickening at the fruits. In the granulated fruits, the pectin is incorporated with the juice to promote gelation formation [18]. Granulation generally starts from the stem end of the fruit pulp and extends towards the stylar end, and the main causes of it are the number of abnormal physiological activities (Table 1).

Water potential is of utmost importance to develop granulation in citrus fruits. Water can easily move within the plant organs from cell to cell due to their different (higher and lower) water potentials. When the SSC and acidity decrease at the fruit cells, these cells are generally turgid with high water potential and are susceptible to lose water to the other adjacent cells (which have lower water potential with higher SSC and low turgor). Researchers suggest that the granulation might be a result of the defensive system of the fruits to lose water [25]. For this purpose, cell wall thickening happens to prevent moisture loss [13]. Previous studies have also showed that polyphenol oxidase (PPO) activity and phenolic contents have a significant influence on granulation where the granulated fruits have lower PPO activity and phenolic content [27].

\section{Effects of Granulation on the Postharvest Storage Quality}

The granulation cause deterioration of fruit quality and hence decreased their marketable value [4, 12]. Granulation is known to reduce the concentrations of SSC and TA which results in developing insipid taste in the fruits [4]. The storage of the granulated fruits is more difficult as compared with the nongranulated normal fruits.

3.1. Effects of Granulation on Mineral Nutrients. Granulation has known to significantly influence the organic acid metabolism of the fruits and have a relationship with 


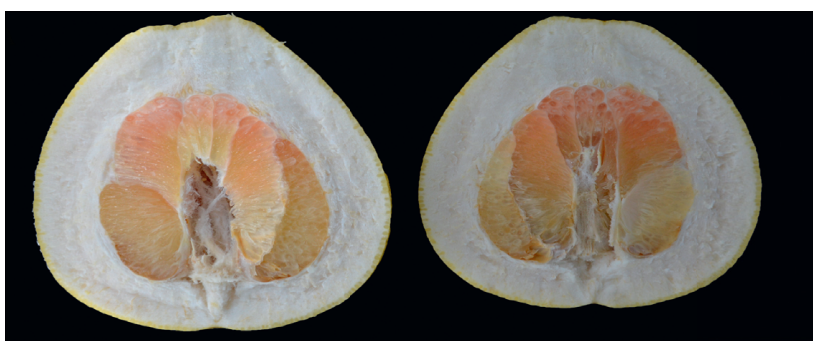

(a)

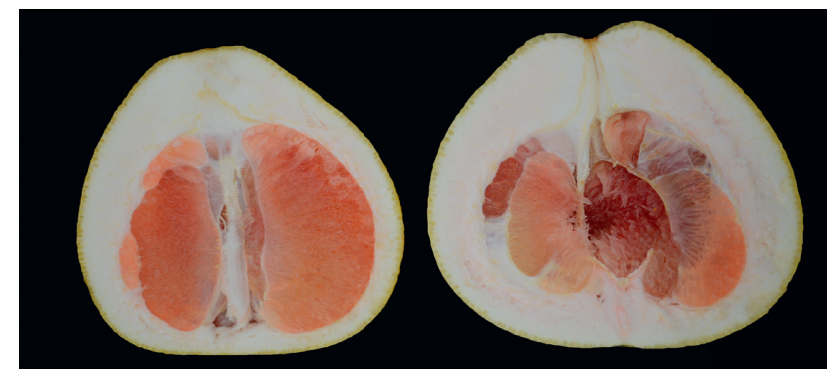

(b)

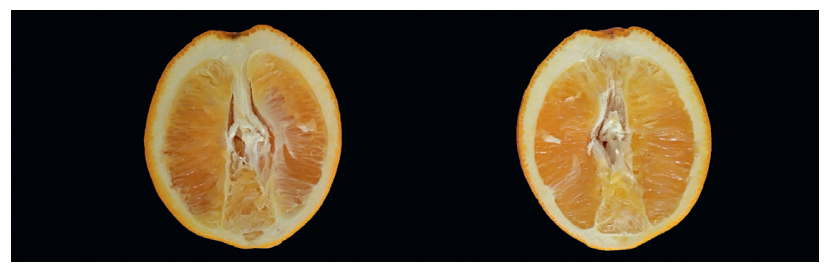

(c)

Figure 1: A view of granulation on the citrus fruits, pummelo fruits (a, b), "Newhall" navel orange (c).

TABLE 1: Main causes of granulation in citrus.

\begin{tabular}{lc}
\hline Causes & Reference \\
\hline $\begin{array}{l}\text { Delay in harvesting and/or late maturity } \\
\text { Vigorous and rapid tree growth }\end{array}$ & {$[4,19,20]$} \\
$\left.\begin{array}{l}\text { Quick ripening } \\
\text { Adverse atmospheric condition: cold weather during the maturity period }\end{array}\right][21]$ & {$[5,20]$} \\
Sink competition among the different plant parts, i.e., fruits, roots, and leaves. & {$[9,22,23]$} \\
Rootstocks and cultivars type & {$[3,24]$} \\
Higher water potential in juice cells & {$[25]$} \\
High temperatures during flowering and fruit set & {$[12]$} \\
Calcium deficiency & {$[20]$} \\
Enzymes activity: polyphenol oxidase (PPO), peroxidase (POD), superoxide dismutase (SOD), catalase (CAT), pectin- & {$[26]$} \\
methylesterase (PME), and cellulose &
\end{tabular}

mineral nutrient contents in the "Guanximiyou" pummelo fruits. Similar to SSC and TA, the granulated juice sacs lead to a decrease in citrate and isocitrate concentrations while an increase in the malate concentration in the citrus fruits. Granulation was also found to enhance the accumulation of mineral nutrients (especially $\mathrm{P}, \mathrm{Mg}, \mathrm{S}, \mathrm{Zn}$, and $\mathrm{Cu}$ ) in juice sacs [28]. Postharvest granulation of "Ponkan" fruits was reported to begin from the stem part of the fruits and extend towards the stylar end of the segment. Yao et al. [29] also conducted a study on "Ponkan" fruits and identified 768 genes which differentially expressed under granulation during the postharvest storage. Among these, researchers determined the genes responsible from enzyme encoding which are involved in the reduction of SSC and TA. In line with these results, Yao et al. [29] suggested that SSC and TA metabolisms are adjusted to the synthesis pathway of the cell wall. In another study, Zhang et al. [30] studied the role of miRNAs in the granulation of citrus fruits. They reported that the miRNAs have a regulating role in lignin processes which relate to citrus granulation during postharvest storage.
3.2. Effects of Granulation on Nutritional Ingredient. Granulation was reported to cause a significant reduction at the concentrations of SSC and TA [4]. Sharma et al. [27] noted that the granulated "Kinnow" mandarin fruits exhibit lower antioxidants activity and ascorbic acid content. Fruit granulation also causes a reduction in the juice content of the citrus fruits resulting in colour change (lighter) of the juice sac $[12,28,31]$. This causes the fruits to have an insipid taste because of the loose of SSC and TA contents. Both SSC and TA of citrus fruit were reported to decrease significantly at the granulated fruits where the sac colour became lighter and caused a decline in the internal fruit quality [27, 32-34].

\subsection{Effects of Granulation on Reactive Oxide Species and Other} Related Enzymes. Some of the fruit enzymes (i.e., polyphenol oxidase (PPO), peroxidase (POD), superoxide dismutase (SOD), and catalase (CAT)) were reported to have a high correlation with the granulation $[3,24,32,35]$. This means that the enzyme activities are higher in granulated fruits as compared with those in the healthy fruits. Wenqin 
et al. [26] have also reported that the inbred pumelo fruits have higher granulation than hybridized fruits. Researchers also noted that no new isoenzymes appear when both inbred and hybridized pumelo fruits are granulated. The activities of isoenzymes of POD and SOD in granulation juicy sac were also reported to be higher than those of the nongranulated fruits. Similar results were also reported by Sharma et al. [24] who noted that the granulated fruits have lower PPO activity and phenolic content. Granulated "Kinnow" mandarin fruits were also reported to exhibit higher lipoxygenase (LOX) enzyme and higher rates of $\mathrm{CO}_{2}$ and ethylene production [24]. On the other hand, recent research has also noted that ROS has some signalling roles on the biotic stress, including fruit granulation [36]. Thus, the evidence suggests that ROS plays an important role in the management of plant stress to different conditions [37].

\subsection{Effects of Granulation on Hydrolase (Pectin Methyl-} esterase, Cellulase, Etc.). Previous studies have also suggested an association of pectin-methylesterase (PME) with citrus granulation [3, 27, 32, 35]. Wu et al. [34] have also reported that the PME's activity is higher in the granulated citrus fruits. They also noted that the pectic acid concentration was also increased in the granulated fruits. In a different study, it was noted that the genes encoding PME catalyze the pectin degradation in citrus fruits [38]. In another study with Ponkan fruits, it was reported that the increase in the levels of those genes improves pectin biosynthesis and leads to an increase in the pectin level granulated juice sacs [29]. Similar results were also previously reported for granulated grapefruits [17].

\section{Detection of Granulation}

It is reported that the detection of the granulation in citrus fruits is almost impossible until cutting the fruits. However, a higher incidence of granulation was reported causing the fruits to feel softer at the last stage of maturity as compared with the healthy fruits. If harvest delays and the severity of the granulation increase, the fruit peel may turn greener, especially around the stem end, as compared with a nongranulated fruit [4]. It is very difficult to reliably detect the granulated fruits without cutting the fruits. Dael et al. [39] developed an algorithm to process fruit images for the detection of granulation. They reported that scanning orange fruits in an X-ray system ( $75 \mathrm{kV}, 468 \mathrm{~mA}, 60$-ms exposure) and processing the images at high-speed and robust algorithm could be used for the detection of the granulation. In another study, researchers aimed to develop a simple and noninvasive technique for the identification of the granulated "Sai Num Pung" tangerine fruits by near-infrared (NIR) spectroscopy and multivariate chemometric analysis. They have analyzed the moisture content, SSC, and TA of the granulated and nongranulated fruits to investigate any relationship among the characteristics. Researchers noted that the idea of using spectroscopic measurement for the identification of the granulation could be successful [40].

\section{Development and Management of Citrus Granulation}

As understood from the mechanism and causes of granulation, there are some important characteristics which significantly affect the fruit granulation. It was reported that granulation can be significantly affected by different characteristics, i.e., rootstock type, yield performance, tree age, and climatic conditions $[4,32]$. Researchers previously reported that the rootstocks which are supporting earliness, on the other hand, promote granulation in fruits. The same phenomena appear on vigorous rootstocks [32, 41]. Granulation in citrus fruits is also reported to be strongly linked with high temperatures during flowering and fruit set [12]. Rootstocks are also known to have an impact on the plant water relationship which might influence the mechanism of granulation [42]. The tree vigour on grafted plants could be associated with the ease movement of water through the rootstocks and scion [43], and this affects the water potential of the plants. Thus, high water potential is known to significantly increase the granulation. There are some previous studies supporting this information where the tree vigour and SSC were reported to be inversely related [44]. Similarly, Hofman [25] reported that the rootstocks have significant influence on the granulation.

Not only the rootstocks and crop load but also the soil type is known to significantly affect tree vigour and fruit development, which indirectly affect the granulation in citrus fruits. Linked with the mechanism, the availability of water is crucial for the granulation and sandy soils have high availability which may increase the fruit granulation $[25,45]$. Fruit size is highly related to the number of fruits per tree and is reported to influence granulation in citrus fruits. A low number of fruits is known to have an increase in fruit size, and granulation is more prevalent in these fruit trees $[3-5,12,25,32]$. The main reason for this relationship is that the SSC and TA concentrations are low in the large fruit which promotes the mechanism of granulation in citrus fruits. The fruit position is also reported by Hofman [25] to significantly influence the granulation. The fruits located inside the canopy are reported to be susceptible to granulation as compared with the outer fruits. This can be associated with the SSC content of the fruits where the fruits inside the canopy are far away to the carbohydrate sources (fewer leaves are found inside the canopy as compared with outside), and it is reported that the leaves generally export their sugar primarily to the nearest fruits [46]. The SSC of the inner fruits is lower than the fruits located outside the canopy.

It was noted that the alcohol-insoluble solids (AISs) (composed of pectin and some cell wall materials) are higher at the granulated fruits [5]. Several studies suggest that the large fruits are more sensitive to granulation $[4,5]$. It was also reported that the harvest time significantly affects the granulation of the Guanxi pomelo (Citrus grandis). Previous studies showed that fruits at low altitudes with timely harvest have high SSC and TA contents and light granulation, but fruits at higher altitudes have delayed maturity than those at 
the lower altitudes; those fruits are reported to have less SSC and TA contents with higher granulation [19]. The above listed factors which influence the development of granulation in citrus made it possible to do some recommendations for its management. The selection of the rootstocks for citrus trees is highly important for successful control of granulation. It could be recommended to select some moderate vigorous rootstocks as compared with high vigorous rootstocks. It is also of utmost importance to regularly irrigate and fertigate plants to promote flowering and ensure early fruit ripening. Adequate application of nitrogen and phosphorus is highly important during the early stages of flowering and fruit set. Regarding the fruit location and SSC contents, tree pruning is also important to ensure adequate light penetration inside the canopy. This would increase the number of leaves inside the canopy, thus increasing the SSC content of the fruits. Fruit thinning can also increase the SSC content of the fruits and may promote earliness, which can reduce the granulation.

Researchers also suggested that the white colour shading net (20\%) could increase the SSC and reduce the granulation at "Ponkan" fruits $[47,48]$. Granulation is reported to be strongly related to the high temperatures during flowering and fruit set [12], and shading net could reduce the incidence of granulation. It is also known that plant nutrition has a significant influence on the granulation development $[28,49]$ and foliar application of macro and micronutrient, i.e., potassium, zinc, calcium, and boron could prevent the development of granulation $[11,50,51]$. Shade netting could also stimulate the development of longer roots [52] which can indirectly improve nutrient uptake and help to reduce the granulation. Among those plant nutrients, calcium was reported to be highly effective in the prevention of granulation in citrus. On the other hand, the selection of cold tolerant and early maturing varieties is suggested [20].

In a different study, Xiong et al. [53] noted that the exogenous application of spermidine (Spd) significantly inhibits the ROS accumulation in "Huangguogan" citrus fruits, when applied to seedlings, and affects antioxidant enzyme activities. Furthermore, researchers suggested that the exogenous Spd application may protect fruits from granulation by improving metabolic defence systems. According to the researchers' notes, exogenous Spd application decreases the permeability of cell membrane (which reduces the water movement) and malondialdehyde (MDA) content of the fruits [53].

\section{Effects of Edible Coatings on Citrus Granulation and Maintaining the Postharvest Quality of Citrus Fruits}

Edible coatings reduce the movement of water (transpiration) and gaseous (indirectly reduces respiration) through the fruits' surface which results in a reduction in the water and solute loss, an increase in antimicrobial activities and hence the improvement in fruit storability $[16,17]$. Edible coatings and films are very important which are developed from edible, environmentally friendly ingredients and have no damage to human health [54]. Because of the consumers' preferences, recent studies have mainly condensed on the development and use of edible coatings in postharvest applications. Edible coatings are reported to be applied to fruits in several forms, including spraying, dipping, and brushing [55]. Edible coatings cover the fresh fruits, seal the stomata, and fill any pores and mechanical cracks $[16,17]$. The main mechanism of the edible coatings for maintaining postharvest quality and storability is because of its characteristics for reducing the gaseous exchange and respiration. However, because of the anaerobic respiration, coatings should not completely inhibit but control gaseous exchange [56]. Therefore, some characteristics of edible coatings, i.e., waxiness, adhesion, thickness, transparency, and plasticity, play a critical role in the success of edible coatings. The characteristics of the fruits are also important for obtaining the desired condition [16].

Edible coatings are generally composed of lipids, proteins, polysaccharides, or from their combinations [57]. These have different advantages and disadvantages in commercial use. For example, lipids provide a good barrier for moisture due to their hydrophobic in nature [16] but have poor characteristic for gas barrier [58]. On the other hand, contrary to lipids, proteins have a good ability to act as a barrier for gaseous exchange, but they are brittle and may have allergenic risks $[58,59]$. Polysaccharides have better characteristics as compared with lipids and proteins and have widely used, such as Aloe vera [60], alginate [61], chitosan [62], and Arabic gum [17]. Combination of multiple coating materials improves functionality of the materials [58]. In general, edible coatings reduce respiration rate $[63,64]$, prevent weight loss [63-65], control ethylene biosynthesis [63, 64, 66], maintain fruit firmness [63-65], prevent colour changes (by controlling anthocyanin and carotenoid synthesis [67]), delay the break-down of soluble solids [64, 65], minimise loss in TA [63-65], reduce the loss of phenolic compounds and ascorbic acid and maintain antioxidant activity [62], delay or control chilling injury [64], and reduce microbial decay [68]. In a previous study, Kharchoufi et al. [68] reported that the edible coatings enriched with pomegranate peel extracts have antifungal effectiveness and reduce Penicillium digitatum decay in orange fruits. Edible coatings with Ficus hirta $+1.5 \%$ sodium alginate treatment was reported to enhance the antioxidant activities of Nanfeng mandarins which also stimulated the accumulation of phenolic compounds and some defencerelated enzymes (i.e., SOD, CAT, POD, chitinase (CHI), and phenylalanine ammonialyase (PAL)) [61]. The senescence of the citrus fruits is generally known as the cause of granulation during postharvest storage, and uncontrolled metabolism reactive oxygen species (ROS) increases the senescence and granulation of the fruits $[69,70]$. Thus, the prevention of the ROS formation inhibits the formation of the granulation. In a previous study, chitosan treatment was reported to reduce the post-harvest oxidative damage, inhibit the $\mathrm{O}_{2}^{-}$production, and MDA accumulation, which reduces the granulation of the "Wuye" lithci fruits. It was also noted that edible coatings enhance the activity of some enzymes, i.e., superoxide dismutase (SOD), ascorbate 
peroxidase (APX), and catalase (CAT) [71]. Edible coatings enhance or induce some enzymatic activities in grapefruits [72] and "Murcott tangor" fruits [73]. Similar results were also reported for "Newhall" navel orange and "Xinyu" tangerines where it was noted that that the chitosan coating forms a protective barrier on the surface and inhibits the oxidation process [74]. This result is in accordance with the previous knowledge about the positive relationship between granulation and oxidative stress [75]. Thus, it can be concluded that the prevention of oxidative stress prevents the granulation of the citrus fruits.

\section{Conclusion and Further Suggestions}

Although there are numerous studies about the mechanism and management of granulation in citrus, it is still an important problem throughout the world and there is not a simple practice for prevention of granulation. Studies suggest that high temperature during flowering, higher water potential of the tree, vigorous tree growth, imbalanced nutrition, cold weather during maturity period, and delay in harvesting are the main reasons for granulation. At this point, another important problem arises which is the drastic change in the world climatic data due to climate change. In line with this information, farmers have to reconsider climatic data when renewing their plantations or establishing new orchards. It is also crucial to pay attention to the rootstock selection, irrigation, and fertilization. Granulation is known to highly affect the postharvest storage life of the citrus fruits, but very few studies have found about the effects of granulation on the postharvest storage duration. It is important to study this subject for the prevention and/or reducing the postharvest granulation. Edible coatings have a great potential in reducing the quality loss during storage and extending the storage duration of citrus fruits. Besides the quality retention, edible coatings provide favourable conditions for reducing oxidative damage and inhibiting $\mathrm{O}_{2}^{-}$production and MDA accumulation, which reduces the citrus fruit granulation. A review of the existing literature also suggests that the edible coatings have high potential in the prevention of the postharvest granulation; however, further studies need to clarify the mode of action and those studies should focus on technological readiness of edible coatings. Commercial performances of edible coatings should be tested by comparing with different applications and by considering its cost and sustainability. This would also make it possible to develop edible coatings industrially, and they will be used for the prevention of citrus fruit granulation during storage.

\section{Data Availability}

No data were used to support this study.

\section{Conflicts of Interest}

The authors declare that they have no conflicts of interest.

\section{Authors' Contributions}

C. W. was responsible for the conceptualization of the study; İ. K., C. C., Z. G., and C. W. investigated the study; I. K. and C. C. reviewed the study; I. K. and C. W. were involved in the discussion; I. K. and C. W. were responsible for writing, reviewing, and editing the original draft; C. W. was involved in the project administration and funding acquisition.

\section{Acknowledgments}

This research was funded by Natural Science Foundation in Jiangxi Province (20181BCB24005).

\section{References}

[1] FAO, FAO Statistics Division, FAO, Rome, Italy, 2019, http:// www.fao.org/faostat/en/\#data/QC.

[2] H. J. Webber, "History and development of the citrus industry," in The Citrus Industry, H. J. Webber and L. D. Batchelor, Eds., University of California Press, Berkeley, CA, USA, 1943.

[3] R. R. Sharma and S. K. Saxena, "Rootstocks influence granulation in Kinnow mandarin (Citrusnobilis $\times$ C. deliciosa)," Scientia Horticulturae, vol. 101, no. 3, pp. 235-242, 2004.

[4] E. T. Bartholomew, W. B. Sinclair, and F. M. Turrel, Granulation of "Valencia" Oranges, Vol. 647, University of California Agricultural Experiment Station Bulletin, CA, USA, 1941.

[5] J. K. Burns and G. L. Albrigo, "Time of harvest and method of storage affect granulation in grapefruit," HortScience, vol. 33, no. 4, pp. 728-730, 1988.

[6] L. Bing and D. L. Shao, "The mechanism of postharvest granulation of Citrus reticulata fruits," Plant Physiology Communications, vol. 3, pp. 5-9, 1988.

[7] R. J. Zong, P. F. Shao, X. O. Hu, and L. Y. Dai, "Preliminary study on fluctuations of components in the juice sac and peel of citrus fruits with granulation," Scientia Agricultura Sinica, vol. 12, no. 3, pp. 60-64, 1979.

[8] R. Singh and R. Singh, "Effect of granulation on physical and chemical characters of the fruit of "Kaula" mandarin," Indian Journal of Agricultural Sciences, vol. 50, pp. 565-568, 1980.

[9] H. Kaur, Y. R. Chanana, and S. P. Kapur, "Effect of growth regulators on granulation and fruit quality of sweet orange cv. Mosambi," Indian Journal of Horticulture, vol. 48, no. 3, pp. 224-227, 1991.

[10] J. Yue ming, L. Shu xian, and C. Fang, "The granulation and control of harvested citrus fruit," Chinese Bulletin of Botany, vol. 8, no. 2, pp. 9-12, 1991.

[11] D. Kotsias, "Influence of Citrus aurantium L. and Poncirus trifoliata (L.) Raf. rootstocks and nutrient sprays on granulation of Valencia sweet orange [C. sinensis (L.) Osbeck] fruits," European Journal of Horticultural Science, vol. 69, no. 4, pp. 244-249, 2004.

[12] M. A. Ritenour, L. G. Albrigo, J. K. Burns, and W. M. Miller, "Granulation in Florida citrus," Proceedings of the Florida State Horticultural Society, vol. 117, pp. 358-361, 2004.

[13] J. K. Burns, "Respiratory rates and glycosidase activities of juice vesicles associated with section-drying in citrus," HortScience, vol. 25, no. 5, pp. 544-546, 1990.

[14] C. Chen, N. Cai, J. Chen, and C. Wan, "UHPLC-Q-TOF/MSBased metabolomics approach reveals the antifungal potential 
of pinocembroside against Citrus green mold phytopathogen," Plants, vol. 9, no. 1, p. 17, 2019.

[15] J. Chen, Y. Shen, C. Chen, and C. Wan, "Inhibition of key citrus postharvest fungal strains by plant extracts in vitro and in vivo: a review," Plants, vol. 8, no. 2, p. 26, 2019.

[16] K. Ncama, L. S. Magwaza, A. Mditshwa, and S. Z. Tesfay, "Plant-based edible coatings for managing postharvest quality of fresh horticultural produce: a review," Food Packaging and Shelf Life, vol. 16, pp. 157-167, 2018.

[17] S. C. Riva, U. O. Opara, and O. A. Fawole, "Recent developments on postharvest application of edible coatings on stone fruit: a review," Scientia Horticulturae, vol. 262, Article ID 109074, 2020.

[18] A. Goto, "Relationship between pectic substances and calcium in healthy, gelated, and granulated juice sacs of sanbokan (Citrus sulcata hort. Ex takahashi) fruit," Plant and Cell Physiology, vol. 30, no. 6, pp. 801-806, 1989.

[19] Z. Donghuang, W. Xianda, S. Hong, and L. Jian, "Citrus grandis "Guanxi pomelo": the relationship between juicy sac granulation and harvesting time," Chinese Agricultural Science Bulletin, vol. 35, no. 26, pp. 64-68, 2019.

[20] K. A. Nxumalo, C. Matsuane, and M. T. Masarirambi, "Calcium-related post-harvest physiological disorders of fruits and vegetables in eswatini: a review," Current Journal of Applied Science and Technology, vol. 33, no. 6, pp. 1-10, 2019.

[21] J. Cassin, J. Bourdeaut, A. Fougue, V. Furon, J. P. Gaillard, and J. LeBourdelles, "The influence of climate upon the blooming of citrus in tropical areas," in Proceedings of First International Citrus Symposium, vol. 1, University of California, Riverside, CA, USA, pp. 315-323, 1969.

[22] M. Agusti, S. Zaragoza, D. J. Iglesias, V. Almela, E. PrimoMillo, and M. Talon, "The synthetic auxin 3,5,6-TPA stimulates carbohydrate accumulation and growth in citrus fruit," Plant Growth Regulation, vol. 36, pp. 43-49, 2002.

[23] V. R. Chakrawar and R. Singh, "Studies on citrus granulation. I. Physical and quality aspects of granulation," Haryana Journal of Horticultural Sciences, vol. 6, no. 3/4, pp. 128-131, 1977.

[24] R. R. Sharma, R. Singh, and S. K. Saxena, "Characteristics of citrus fruits in relation to granulation," Scientia Horticulturae, vol. 111, no. 1, pp. 91-96, 2006.

[25] H. Hofman, "Management of internal dryness of imperial mandarin," Horticulture Australia Ltd, Sydney, Queensland, Australia, CT04002, 2011.

[26] S. Wenqin, Z. Xiaoling, P. Dongming, and L. Zhongxiong, "A study on the changes in isoenzymes of in the process of "Guanxi" pummelo juicy sac granulation," Chinese Agricultural Science Bulletin, vol. 24, no. 7, pp. 294-298, 2008.

[27] R. R. Sharma, O. P. Awasthi, and K. Kumar, "Pattern of phenolic content, antioxidant activity and senescence-related enzymes in granulated vs non-granulated juice-sacs of "Kinnow" mandarin (Citrus nobilis x C. deliciosa)," Journal of Food Science and Technology, vol. 53, no. 3, pp. 1525-1530, 2016.

[28] X.-Y. Wang, P. Wang, Y.-P. Qi et al., "Effects of granulation on organic acid metabolism and its relation to mineral elements in Citrus grandis juice sacs," Food Chemistry, vol. 145, pp. 984-990, 2014.

[29] S. Yao, Q. Cao, J. Xie, L. Deng, and K. Zeng, "Alteration of sugar and organic acid metabolism in postharvest granulation of Ponkan fruit revealed by transcriptome profiling," Postharvest Biology and Technology, vol. 139, pp. 2-11, 2018.

[30] J. Zhang, M. Wang, F. Cheng et al., "Identification of microRNAs correlated with citrus granulation based on bioinformatics and molecular biology analysis," Postharvest Biology and Technology, vol. 118, pp. 59-67, 2016.

[31] J. L. Wu, T. F. Pan, Z. X. Guo, and D. M. Pan, "Specific lignin accumulation in granulated juice sacs of Citrus maxima," Journal of Agricultural and Food Chemistry, vol. 62, no. 50, Article ID 12082, 2014.

[32] R. P. Awasthi and J. P. Nauriyal, "Studies on granulation in sweet orange. II. Differences in moisture, total soluble solids and ascorbic acid of juice vesicles in different stages of granulation," Punjab Horticultural Journal, vol. 12, pp. 203-211, 1972.

[33] J. Burdon, N. Lallu, C. Yearsley, S. Osman, D. Billing, and H. Boldingh, "Postharvest conditioning of Satsuma mandarins for reduction of acidity and skin puffiness," Postharvest Biology and Technology, vol. 43, no. 1, pp. 102-114, 2007.

[34] L.-M. Wu, C. Wang, L.-G. He et al., "Transcriptome analysis unravels metabolic and molecular pathways related to fruit sac granulation in a late-ripening navel orange (Citrus sinensis osbeck)," Plants, vol. 9, no. 1, p. 95, 2020.

[35] R. Singh, "65-year research on citrus granulation," Indian Journal of Horticulture, vol. 58, no. 1-2, pp. 112-144, 2001.

[36] M. J. Considine, L. María Sandalio, and C. Helen Foyer, "Unravelling how plants benefit from ROS and NO reactions, while resisting oxidative stress," Annals of Botany, vol. 116, no. 4, pp. 469-473, 2015.

[37] A. Molassiotis, D. Job, V. Ziogas, and G. Tanou, "Citrus plants: a model system for unlocking the secrets of NO and ROS-inspired priming against salinity and drought," Frontiers in Plant Science, vol. 7, p. 229, 2016.

[38] D. Mohnen, "Pectin structure and biosynthesis," Current Opinion in Plant Biology, vol. 11, no. 3, pp. 266-277, 2008.

[39] V. M. Dael, E. Herremans, V. Verboven, U. L. Opara, B. Nicolai, and S. Lebotsa, "Automated online detection of granulation in oranges using X-ray radiographs," Acta Horticulturae, vol. 1119, pp. 179-182, 2016.

[40] P. Theanjumpol, K. Wongzeewasakun, N. Muenmanee et al., "Non-destructive identification and estimation of granulation in "Sai Num Pung" tangerine fruit using near infrared spectroscopy and chemometrics," Postharvest Biology and Technology, vol. 153, pp. 13-20, 2019.

[41] J. S. Jawanda, D. K. Uppal, R. Singh, and J. S. Arora, "Studies on granulation in citrus fruits," Punjab Horticultural Journal, vol. 18, pp. 180-188, 1978.

[42] W. S. Castle and I. J. Warrington, "Rootstock as a fruit quality factor in citrus and deciduous tree crops," New Zealand Journal of Crop and Horticultural Science, vol. 23, no. 4, pp. 383-394, 1995.

[43] J. P. Syvertsen and J. H. Graham, "Hydraulic conductivity of roots, mineral nutrition, and leaf gas exchange of citrus rootstocks," Journal of the American Society for Horticultural Science, vol. 110, pp. 865-869, 1985.

[44] Y. Yonemoto, K. Matsumoto, T. Furukawa, M. Asakawa, H. Okuda, and T. Takahara, "Effects of rootstock and crop load on sap flow rate in branches of "Shirakawa Satsuma" mandarin (Citrus unshiu Marc.)," Scientia Horticulturae, vol. 102, no. 3, pp. 295-300, 2004.

[45] G. Fullelove, K. Walsh, P. Subedi, R. Shaw, and G. Pinnington, "Management of internal dryness of imperial mandarins," Horticulture Australia Limited, Rockhampton, Australia, CT03029, 2004.

[46] P. Kriedemann, "The distribution of ${ }^{14} \mathrm{C}$-labelled assimilates in mature lemon trees," Australian Journal of Agricultural Research, vol. 21, no. 4, pp. 623-632, 1970.

[47] T.-C. Lee, P.-J. Zhong, and P.-T. Chang, "The effects of preharvest shading and postharvest storage temperatures on 
the quality of "Ponkan" (Citrus reticulata Blanco) mandarin fruits," Scientia Horticulturae, vol. 188, pp. 57-65, 2015.

[48] A. Mditshwa, L. S. Magwaza, and S. Z. Tesfaya, "Shade netting on subtropical fruit: effect on environmental conditions, tree physiology and fruit quality," Scientia Horticulturae, vol. 256, Article ID 108556, 2019.

[49] R. Sinha, K. Karuna, M. F. Ahmad, M. Prasad, G. Singh, and A. Mankar, "Effect of fertigation on granulation in Kinnow mandarin," Journal of Pharmacognosy and Phytochemistry, vol. 8, no. 3, pp. 2648-2651, 2019.

[50] S. K. Munshi, R. Singh, V. K. Vij, and J. S. Jawanda, "Mineral composition of leaves in relation to degree of granulation in sweet orange," Scientia Horticulturae, vol. 9, no. 4, pp. 357367, 1978.

[51] R. Jawanda and R. Singh, "Effect of nutrient sprays on granulation and fruit quality of "Dancy tangerine" mandarin," Scientia Horticulturae, vol. 14, no. 3, pp. 235-244, 1981.

[52] K. Zhou, D. Jerszurki, A. Sadka, L. Shlizerman, S. Rachmilevitch, and J. Ephrath, "Effects of photoselective netting on root growth and development of young grafted orange trees under semi-arid climate," Scientia Horticulturae, vol. 238, pp. 272-280, 2018.

[53] B. Xiong, S. Ye, X. Qiu et al., "Exogenous spermidine alleviates fruit granulation in a Citrus cultivar (Huangguogan) through the antioxidant pathway," Acta Physiologiae Plantarum, vol. 39, no. 4, p. 98, 2017.

[54] S. Galus and J. Kadzińska, "Food applications of emulsionbased edible films and coatings," Trends in Food Science \& Technology, vol. 45, no. 2, pp. 273-283, 2015.

[55] E. Tavassoli-Kafrani, H. Shekarchizadeh, and M. Masoudpour-Behabadi, "Development of edible films and coatings from alginates and carrageenans," Carbohydrate Polymers, vol. 137, pp. 360-374, 2016.

[56] T. S. Parreidt, K. Müller, and M. Schmid, "Alginate-based edible films and coatings forfood packaging applications," Foods, vol. 7, no. 10, pp. 1-38, 2018.

[57] B. Hassan, S. A. S. Chatha, A. I. Hussain, K. M. Zia, and N. Akhtar, "Recent advances on polysaccharides, lipids and protein based edible films and coatings: a review," International Journal of Biological Macromolecules, vol. 109, pp. 1095-1107, 2018.

[58] H. Arnon-Rips and E. Poverenov, "Improving food products' quality and storability by using layer by layer edible coatings," Trends in Food Science \& Technology, vol. 75, pp. 81-92, 2018.

[59] D. Lin and Y. Zhao, "Innovations in the development and application of edible coatings for fresh and minimally processed fruits and vegetables," Comprehensive Reviews in Food Science and Food Safety, vol. 6, no. 3, pp. 60-75, 2007.

[60] İ Kahramanoğlu, C. Chen, J. Chen, and C. Wan, "Chemical constituents, antimicrobial activity, and food preservative characteristics of aloe vera gel," Agronomy, vol. 9, no. 12, p. 831, 2019.

[61] C. Chen, X. Peng, R. Zeng, M. Chen, C. Wan, and J. Chen, "Ficus hirta fruits extract incorporated into an alginate-based edible coating for Nanfeng mandarin preservation," Scientia Horticulturae, vol. 202, pp. 41-48, 2016.

[62] A. K. Baswal, H. S. Dhaliwal, Z. Singh, B. Mahajan, A. Kalia, and K. S Gill, "Influence of carboxy methylcellulose, chitosan and beeswax coatings on cold storage life and quality of Kinnow mandarin fruit," Scientia Horticulturae, vol. 260, Article ID 108887, 2020.

[63] H. Arnon, Y. Zaitsev, R. Porat, and E. Poverenov, "Effects of carboxymethyl cellulose and chitosan bilayer edible coating on postharvest quality of citrus fruit," Postharvest Biology and Technology, vol. 87, pp. 21-26, 2014.

[64] B. Saberi, J. B. Golding, J. R. Marques et al., "Application of biocomposite edible coatings based on pea starch and guar gum on quality, storability and shelf life of "Valencia" oranges," Postharvest Biology and Technology, vol. 137, pp. 9-20, 2018.

[65] E. Motamedi, J. Nasiri, T. R. Malidarreh, S. Kalantari, M. R. Naghavi, and M. Safari, "Performance of carnauba waxnanoclay emulsion coatings on postharvest quality of "Valencia" orange fruit," Scientia Horticulturae, vol. 240, pp. 170-178, 2018.

[66] C. Rojas-Argudo, M. A. del Río, and M. B. Pérez-Gago, "Development and optimization of locust bean gum (LBG)based edible coatings for postharvest storage of "Fortune" mandarins," Postharvest Biology and Technology, vol. 52, no. 2, pp. 227-234, 2009.

[67] T. A. A. Nasrin, M. A. Rahman, M. S. Arfin, M. N. Islam, and M. A. Ullah, "Effect of novel coconut oil and beeswax edible coating on postharvest quality of lemon at ambient storage," Journal of Agriculture and Food Research, vol. 2, Article ID 100019, 2020.

[68] S. Kharchoufi, L. Parafati, F. Licciardello et al., "Edible coatings incorporating pomegranate peel extract and biocontrol yeast to reduce Penicillium digitatum postharvest decay of oranges," Food Microbiology, vol. 74, pp. 107-112, 2018.

[69] S. S. Gill and N. Tuteja, "Reactive oxygen species and antioxidant machinery in abiotic stress tolerance in crop plants," Plant Physiology and Biochemistry, vol. 48, no. 12, pp. 909930, 2010.

[70] R. Mittler, "ROS are good," Trends in Plant Science, vol. 22, no. 1, pp. 11-19, 2017.

[71] X. Jiang, H. Lin, J. Shi et al., "Effects of a novel chitosan formulation treatment on quality attributes and storage behavior of harvested litchi fruit," Food Chemistry, vol. 252, pp. 134-141, 2018.

[72] A. M. Lin, E. Aispuro-Hernández, I. Vargas-Arispuro, M. A. Islas-Osuna, and M. Á. Martínez-Téllez, "Expression of antioxidant-related genes in flavedo of cold-stored grapefruit (Citrus paradisi Macfad cv. Rio Red) treated with pectic oligosaccharides," Scientia Horticulturae, vol. 243, pp. 274-280, 2019.

[73] P.-J. Chien, F. Sheu, and H.-R. Lin, "Coating citrus (Murcott tangor) fruit with low molecular weight chitosan increases postharvest quality and shelf life," Food Chemistry, vol. 100, no. 3, pp. 1160-1164, 2007.

[74] C. Chen, Z. Nie, C. Wan, and J. Chen, "Preservation of Xinyu tangerines with an edible coating using Ficus hirta Vahl. fruits extract-incorporated chitosan,” Biomolecules, vol. 9, no. 2, p. 46, 2019.

[75] J. M. Sala, "Involvement of oxidative stress in chilling injury in cold-stored mandarin fruits," Postharvest Biology and Technology, vol. 13, no. 3, pp. 255-261, 1998. 